\title{
Acquired Factor VII deficiency associated with pneumonia
}

\author{
Pnömoni ile birlikte kazanılmış Faktör VII eksikliği \\ Osman Yokuş', Özlem Şahin Balçık², Murat Albayrak ${ }^{3}$ \\ ${ }^{1}$ Okmeydanı Education and Research Hospital Department of Hematology, Istanbul, Turkey \\ ${ }^{2}$ Fatih University Medical School Department of Hematology, Ankara, Turkey \\ ${ }^{3}$ Dışkapı Yıldırım Beyazıt Education and Research Hospital Department of Hematology, Ankara, Turkey
}

\section{Dear Editor,}

Factor VII (FVII) deficiency is a rare autosomal recessive congenital coagulopathy associated with clinical bleeding and isolated prolongation of the prothrombin time (PT). Factor VII deficiency may present with hemorrhages of central nervous (CNS) and gastrointestinal (GIS) systems during infantile period or may be asymptomatic until adulthood. ${ }^{1}$ However, acquired factor VII deficiency is extremely rare. .,3,4,5 Although there are numerous reports regarding the use of rFVIla concentrate in patients with hemorrhage owing to congenital FVII deficiency, little is known about secondary FVII deficiency and its management. Here, we present the first report of an acquired FVII deficiency developed in an elderly woman during the course of communityacquired pneumonia and discuss management approaches for this very rare entity.

An 83-year-old woman presented to our hematology clinic with three-day history of multiple ecchymoses of the left upper extremity and one week history of fever, productive cough and fatigue. She had no evidence of bleeding diathesis in the past and gave a negative family history of bleeding. Physical examination showed a mild cooperation and orientation defect. She had a temperature of $38.50 \mathrm{C}$ and a blood pressure of $140 / 90 \mathrm{~mm} / \mathrm{Hg}$. She had widespread ecchymoses of the skin and multiple subcutaneous hematomas of bilateral upper extremities, which was more prominent at the left upper extremity (Picture 1). Examination of the lungs showed inspiratory crackles at the middle part and the base of the right lung. Laboratory findings were as follows; white blood cell count: $11 \times 109 / /$, hemoglobin $10 \mathrm{~g} / \mathrm{dl}$, Platelets 296x109/l, Prothrombin time 23 sec., INR: 1.93, activated partial throm- boplastin time (aPTT) $32 \mathrm{sec}$. fibrinogen: $821 \mathrm{mg} /$ $\mathrm{dL}$, erythrocyte sedimentation rate: $51 \mathrm{~mm} / \mathrm{hr}$, Lactic dehydrogenase $323 \mathrm{U} / \mathrm{L}(140$ - 280). Renal and liver function tests were within the normal ranges. Tumor markers and anti-cardiolipin antibodies were also normal. Factor VII plasma level measured was 3.4\% (normal range, 50-150\%). Levels of the factors II, V, VIII, IX, X and von-Willebrand factor were within the normal ranges. Normal plasma pooled with equal amount of patient's plasma was mixed and PT and aPTT tests were repeated. It was seen with mixture test that PT and aPTT levels returned to normal at 0 hour and at the end of $2^{\text {nd }}$ hour still remained within normal limits and the presence of an inhibitor which may have developed against coagulation factors was ruled out. All factor levels were measured before the transfusion of fresh frozen plasma (FFP). A chest $\mathrm{x}$-ray revealed consolidative infiltrations of the middle and the lower lobes of the right lung consistent with pneumonia. The patient was immediately started on levofloksasin $500 \mathrm{mg} /$ day after the diagnosis of community-acquired pneumonia was made. She was concomitantly given FFP at the dose of 15 $\mathrm{ml} / \mathrm{kg}$ q6h and vitamin K. A control FVII plasma level sent out to a reference laboratory before the transfusion of FFP was reported to be $2 \%$. Therefore, a diagnosis of acquired FVII deficiency was made. Weakening of pulsation in the left upper extremity was obtained during the follow up of the patient. The patient was monitored for progression to compartment syndrome secondary to the hematoma.

There was no resolution of her clinical and laboratory findings with FFP transfusions and vitamin $\mathrm{K}$ administrations, a decision was made to treat the patient with rFVIla concentrate. On the third day of her hospitalization, she was given Eptagog alfaÒ (rFVIla concentrate) $30 \mathrm{mcg} / \mathrm{kg}$ tid for three days. 
There was a prompt response to the treatment with gradual resolution of the widespread hematomas (Picture 2). Her pneumonia responded well to the antibiotic treatment. Her clinical findings completely improved within a week and she was discharged from the hospital. Two weeks after her discharge, haemostatic parameters were completely normal including complete blood count, PT, aPTT with a plasma FVII level of $59.1 \%$.

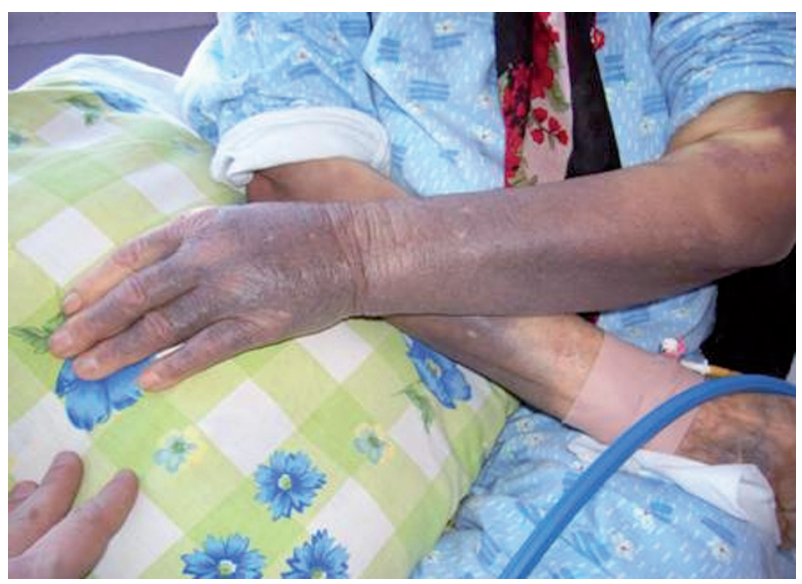

Picture 1. Subcutaneous hematomas of the left upper extremity at presentation

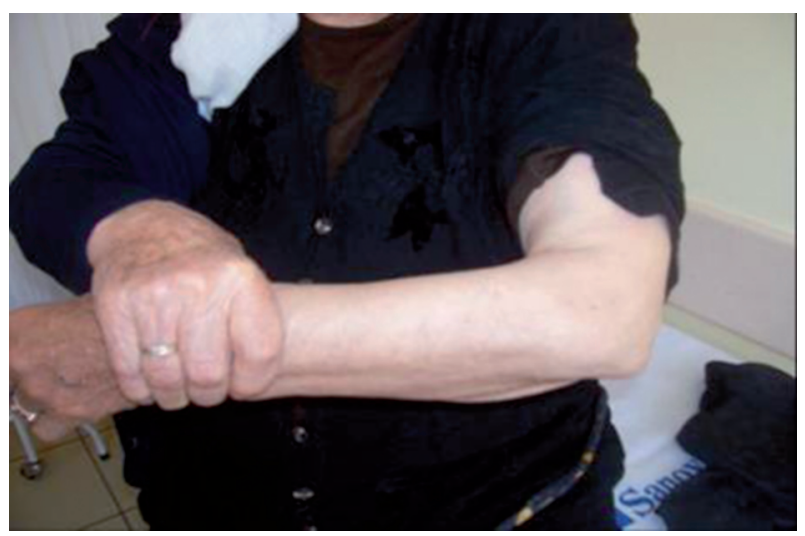

Picture 2. Complete resolution of the subcutaneous hematomas of the left upper extremity one week after the treatment

Congenital factor VII deficiency is a rare hereditary coagulopathy with a prevalence of 1 in 500.000 populations. It usually causes a bleeding tendency from mucosal membranes. ${ }^{1}$ Although, it is a congenital disease, the age of the patients at the clinical onset may differ depending on the severity of the deficiency. Central nervous system and gastrointestinal hemorrhages may be seen as early as infantile period. ${ }^{6}$ In our case, an elderly patient was hospitalized with community acquired pneumonia and widespread ecchymoses and multiple subcutaneous hematomas of the bilateral upper extremities; haemostatic work up showed prolonged PT, and FVII was measured at a very low level of $2 \%$. Given her negative personal and family history of bleeding in the past and the clinical picture of pneumonia, the diagnosis of an acquired FVII deficiency associated with community-acquired pneumonia was made. To our knowledge, this is the first report of an acquired FVII deficiency during the course of communityacquired pneumonia. This is in accordance with a few reports indicating that sepsis and leukemia may trigger secondary FVII deficiency and that appropriate treatment of the underlying disease may correct the abnormally elevated haemostatic parameters. ${ }^{7,8}$ Although, isolated FVII consumption or proteolytic degradation by leukocyte proteases have been suggested as the possible causes of acquired FVII deficiency, definitive cause is unknown. ${ }^{7,8}$ FFP was administered to our patient as the initial treatment, however it did not improve PT levels and the level of FVII did not increase. This was due to isolated FVII consumption or insufficient activation of FVII coagulation in FFP owing to the proteolytic degradation.

Concentrates of rFVIla have been successfully used for the management of bleeding owing to FVII deficiency. ${ }^{7,9,10}$ It has also been suggested that maintaining plasma FVII level at $5-10 \%$ might control spontaneous or post-traumatic clinical bleeding and that FFP might be used for this purpose. Similarly, in our case, the patient was initially treated with vitamin $\mathrm{K}$ and transfusions of FFP q6h for 3 days with no clinical and laboratory response. Therefore, rFVIla concentrate was administered at the dose of $30 \mathrm{mcg} / \mathrm{kg}$ tid for three days with complete improvement of the clinical and laboratory findings within a week. Moreover, it is likely that the treatment of the pneumonia might have a considerable impact on the reversal of the hemostatic defect.

In conclusion, acquired factor VII deficiency may be seen during the course of community-acquired pneumonia and should also be considered within differential diagnosis of the hemostatic defects in elderly patients with infection and no history of bleeding in the past. Treatment includes replacement therapy as well as the treatment of underlying infection.

\section{REFERENCES}

1. Iannello S, Prestipino M, Belfiore F. Genetic deficiency of factor VII and hemorrhagic diathesis. A case report and literature review. Panminerva Med 1998;40(3):226-38. 
2. Peyvandi F, Cattaneo M, Inbal A, De Moerloose P, Spreafico M. Rare bleeding disorders. Haemophilia 2008;14 Suppl 3:202-10.

3. Croom KF, McCormack PL. Recombinant factor Vila (eptacog alfa): a review of its use in congenital hemophilia with inhibitors, acquired hemophilia, and other congenital bleeding disorders. BioDrugs 2008;22(2):121-36.

4. Lim S, Zuha R, Burt T, Chacko J, Scott R, Mainwaring CJ. Life-threatening bleeding in a patient with a lupus inhibitor and probable acquired factor VII deficiency. Blood Coagul Fibrinolysis 2006; 17(8):667-71.

5. Siddiqui MA, Scott LJ. Recombinant factor Vila (Eptacog Alfa): a review of its use in congenital or acquired haemophilia and other congenital bleeding disorders. Drugs 2005;65(8):1161-77.

6. Peyvandi F, Mannucci P.M, Asti D, Abdoullahi M, Di Rocco N, Sharifian R. Clinical manifestations in 28
Italian and Iranian patients with severe factor VII deficiency. Haemophilia 1997;3: 242-6.

7. White B, Martin M, Kelleher S, Browne P, McCann SR, Smith OP. Successful use of recombinant FVIla (Novoseven) in the management of pulmonary haemorrhage secondary to Aspergillus infection in a patient with leukaemia and acquired FVII deficiency. $\mathrm{Br} \mathrm{J}$ Haematol 1999;106(1):254-5.

8. Biron C, Bengler C, Gris JC, Schved JF. Acquired isolated factor VII deficiency during sepsis. Haemostasis 1997;27(2):51-6.

9. Mullighan CG, Rischbieth A, Duncan EM, Lloyd JV. Acquired isolated factor VII deficiency associated with severe bleeding and successful treatment with recombinant FVIIa (NovoSeven). Blood Coagul Fibrinolysis 2004;15(4):347-51.

10. Franchini M. Recombinant factor VIla: a review on its clinical use. Int J Hematol 2006;83(2):126-38. 